\title{
Responsabilidade Fiscal (2000)
}

Diogo de Figueiredo Moreira Meto

\section{Introdução}

Uma triste tradição de irresponsabilidade fiscal e orçamentária dos governantes brasileiros, em que o gastar mais do que se arrecada, o iniciar obras sem saber se é possível terminá-las, o superfaturar para obter proveitos ilícitos, o paralisar investimentos iniciados pelo antecessor e o endividar os erários, entre outras mazelas administrativas do mesmo jaez, que se incorporaram ao quotidiano político, parece estar, enfim, com seus dias contados, assim como o flagelo da inflação, inevitável produto dessas práticas obnóxias.

E possível que, com o advento da Lei Complementar $n^{0} 101$, de 4 de maio de 2000 , a Lei de Responsabilidade Fiscal, o País esteja superando uma das mais terríveis barreiras a seu desenvolvimento sustentado, isso não só pelo atingimento do equilíbrio das contas públicas, um efeito visível, como, e principalmente, pelos ganhos de legitimidade democrática, um efeito invisível, mas muito mais profundo e duradouro.

Inaugura-se um novo conceito de gestão fiscal, em que o equilíbrio das contas públicas erige-se em dever do administrador público que, para cumpri-lo cabalmente, além de sua sujeição à legalidade, precisa ainda submeter-se à legitimidade, inclusive no exercício obrigatório da prudência fiscal.
Esse novo conceito vem claramente expresso no art. $10, \S 10$, da Lei, em que se define a responsabilidade fiscal e os tópicos a ela pertinentes nos seguintes termos:

“A responsabilidade na gestão fiscal pressupoe a ação planejada transparente, em que se previnem riscos e corrigem desvios capazes de afetar o equilíbrio das contas públicas, mediante o cumprimento de metas de resultados entre receitas e despesas e a obediência a limites e condições no que tange a renúncia de receita, geração de despesas com pessoal, da seguridade social e outras, dividas consolidada e mobiliária, operações de crédito inclusive por antecipação de receita concessão de garantia e inscrição em Restos a Pagar."

A compreensão dessa evolução conceptual, em seus aspectos políticos, econômicos e jurídicos é indispensável para a tarefa que se impõe, necessária e patriótica, mas nem sempre fácil, de interpretar e de aplicar a nova legislação de finanças públicas.

Esta Lei, embora represente uma importante conquista da racionalidade e da democracia na administração pública, apresenta dificuldades de toda sorte, desde questões

Foram destacados no texto os elementos inovadores introduzidos pela Legislação. 

a evolução principiológica trazida ao Direito

Sob o ângulo político, o aspecto mais um conteúdo material, apto a lastrear um modelo apenas como um processo formal de escolha de teóricas, como seja a sua inserção juspolítica, que são importantes para sua compreensão, às eminentemente práticas, suscitadas pelos preceitos de seu articulado, tudo demandando atenção e estudo, com vistas ao necessário e árduo trabalho interpretativo a ser enfrentado, que recairá sobre seus milhares de aplicadores e, inevitavelmente, confluirá para os tribunais do País.

Para tanto, serão reexaminados, como pano de fundo, conceitos sobre democracia, economia e finanças públicas, para, em relação a eles, tecer algumas considerações sobre temas como insolvência pública, segurança jurídica e estabilidade financeira. A seguir, depois de lembrados alguns precedentes institucionais. serão apresentadas algumas conclusões sobre Financeiro e sobre a experiência brasileira, encerrando-se com algumas breves conclusões.

\section{Considerações Políticas} importante a ser realçado é que a evolução das finanças públicas passa a refletir as recentes modificações do conceito de democracia, que transcendeu de um conteúdo positivista e formal, que tinha sido satisfatório para estruturar um Estado de Direito, para apresentar também de Estado Democrático de Direito.

Com efeito, tem-se hoje assente que a democracia não pode mais ser considerada quem nos deve governar, mas, também, de uma escolha de como queremos ser governados.

É com essa concepção, de um valor substantivo, a ser realizado pelas sociedades, elevada por isso ao rol dos princípios fundamentais nas Constituições contemporâneas, que a democracia passa a se incorporar ao elenco dos direitos fundamentais das pessoas, indissoluvelmente ligada à liberdade e à igualdade.

Muito a propósito, EDUARDO GARCÍA DE ENTERRÍA, sem favor, dos mais importantes juristas da atualidade, em magistral trabalho, Democracia, Juizes e Controle da Administraçã $o^{2}$, assim a sintetiza essa evolução:

"todos nós nos submetemos às Leis adotadas sobre a base de uma decisão comum dos membros da coletividade, iguais em direitos, mas a democracia tem um componente liberal essencial, pois, além do direito à participação na formação dessa vontade geral, o cidadão não se submete inteiramente a ela, pois permanece como titular de direitos fundamentais próprios, indissociáveis da personalidade e da dignidade humanas, e que limitam o poder político. Daí resulta que liberdade, igualdade de direitos e democracia, são indivisíveis".

Mas essa ascensão da democracia, entendida em seu valor substantivo, ao elenco dos direitos fundamentais, tampouco passou despercebida fora do âmbito do pensamento jurídico, como bem o atestam ilustres sociólogos e politicólogos contemporâneos, que mais recentemente trataram o tema, como, destacadamente, NORBERTO BOBBIO 3 e ROBERT A $\mathrm{DAHL}^{4} \mathrm{e}$, na linha desses predecessores, GIOVANNI SARTORP' ALAINTOURAINE

2 EDUARDO GARCÍA DE ENTERRÍA, Democracia, Jueces y Control de la Administración, Madri, Civitas, 5 edição ampliada, 2000, ps. 66 a 84 (n/ adaptaçāo).

ROBERT A. DAHL, Pollarchy. Participation and opposition, N. York, 1971.

GIOVANNI SARTORI, Theory of Democracy revisited, 1987, apud trad. espanhola Teoria de la democracia Madri, Alianza, 2 volumes, 1988. Há uma edição compendiada posterior: Democrazia. Cosa è, Milão, Rizzoli, 1993. 6 ALAIN TOURRAINE, Qu'est ce que la démocratie?, Paris, Fayard, 1994.

Revista da Faculdade de Direito da UFRGS, v. 21, Março/2002
NORBERTO BOBBIO, Il Futuro de la democrazia. Le regole del gioco, Turim, 1986
Assim é que ALAIN TOURAINE, após considerações sobre os processos formais que são, efetivamente, os direitosfundamentais dos cidadãos, "os verdadeiros fundamentos da ordem política e da paz social"?

Dá prosseguimento, assim, o notável sociólogo francês, à mesma linha de pensamento do não menos celebrado teórico político italiano, GIOVANNI SARTORI, que depois de assinalar que a democracia não é, pura e simplesmente, "o governo da maioria", mas o é "o governo da maioria limitada", explica que isso se dá porque o cidadão não perde a sua liberdade com a expressão formal de seu voto, mas, ao contrário, por se tratar de um regime aberto, "a manutenção da democracia como um processo em marcha nos exige assegurar que todos os cidadãos (maioria plus minoria) ostentem os direitos que o método requer, através do qual a democracia opera". ${ }^{8}$

Essa nova concepção contrasta fortemente com a que prevaleceu em grande parte do Século XX, período em que se considerou possível e até comum uma coexistência da democracia com regímes e governos de corte autocrático, fortemente estatizantes, socialistas e, até mesmo, violentamente despóticos, dispensando-se relembrar tantos infaustos exemplos desse hoje, incompreensível hibridismo.

Modernamente muito se tem escrito sobre as relações entre economia e democracia, principalmente sob o acicate da motivação trazida pela dimensão do fenômeno da exclusão econômica, que atinge grandes massas

populacionais do planeta e que se veio agudizando desde o Século XIX e durante todo o Século XX, para se tornar particularmente mais grave nos países em desenvolvimento, embora se apresente não menos aflitiva, naqueles tidos como desenvolvidos.

Ora, se é certo que a exclusão econômica leva à exclusão política, e isso não se discute, o que é mais espantoso e verificar-se, como resultado das pesquisas lavadas a cabo no último lustro sobre o agigantamento do setor informal da economia, que, nas democracias emergentes ${ }^{9}$, essa exclusão econômica em escala planetária vem a ser nada menos que 0 resultado acumulado de políticas públicas equivocadas, que, não obstante, continuam a ser mantidas, arraigadas à crença de que ainda é possível resolver novos e magnos problemas, como este, da exclusão, nesta virada do Século, com fórmulas, concepções e ideologias novecentistas, como as dos surrados ismos.

Esse estranho conservadorismo, que se situa entre a acomodação, a indecisão e o acovardamento ante os grandes desafios emergentes, embora paradoxalmente insista em anacrônica fidelidade ao "progresso", arraigase a velhas fórmulas cerebrinas do passado, que foram, por ironia, as mesmas que terminaram por produzir todos esses milhões de excluídos, durante tantas décadas de fastígio dos dois principais modelos de Estado-providência vigentes: o do Bem Estar Social e o Socialista.

Vem a ser, portanto, uma amarga ironia, que esses milhões de excluídos que adentram o Século XXI, sejam, afinal, filhos das mesmas próprios da democracia, acaba por reconhecer

ALAIN TOURAINE, op, cit., p. 264.

${ }^{8}$ GIOVANNI SARTORI, op. cit., p.58 (n/ negrito na citação).

9 Um bom resumo e esclarecedora bibliografia podem ser compulsados no documento Backgroud Paper Barriers to Participation: The Informal Sector in Emerging Democracies, produzido por CATHERINE KUCHTAHEBLING, para o Center for International Private Enterprise - CIPE, disponível na Web Page http:// www.cipe.org, Copyright CIPE, 2000

Revista da Faculdade de Direito da UFRGS, v. 21, Março/2002 
políticas autocráticas, estatizantes e socializantes, que dominaram o Estado-nação por tanto tempo, e, não obstante, aí continuam, aberta ou esconsamente, pouco importa, a ser cultuadas pelos que, secretamente, namoram o autoritarismo e desconfiam da liberdade, aliás, como sempre o fizeram, porém, uma vez professadas, por aqueles que não aprenderam com a História, procuram disfarçá-las em versões criptodemocráticas, abusando de úm conceito cujo conteúdo material jamais entenderam.

São, invariavelmente, esses mesmos, que insistindo nas fórmulas do passado, os que mais se opõem às reformas que podem resgatar os excluídos, confundindo e procurando que se confunda, em estranha militância política feita com os olhos postos no retrovisor, a democracia formal, que conhecem, e que se demonstrou ser uma democracia excludente, com a nova democracia substancial, que não conhecem, e, até por definição, por ser fundamentalmente participativa, é, ao revés, uma democracia includente.

Mesmo que se lhes conceda, aos inefáveis cultores dos extremismos políticos do passado, o benefício da boa fé, até o de serem cristãos novos da democracia, há sempre o risco, neste mundo de riscos crescentes, de virem a ressuscitar, ao primeiro descuido, o flagelo de suas crenças deletérias, que ressurgiriam, apresentadas com o estrépito das militâncias, como alternativas eficientes de poder, que estariam aptas a produzir resultados materiais, mais rapidamente do que é possível através do que se sabe ser um lento e paciente exercício das soluções democráticas.

Ora, uma democracia substantiva, para sua prática, não pode depender apenas do sufrágio eletivo de representantes, exigindo, cada vez mais, uma decidida abertura àparticipação, com a derrubada dos

remanescentes dos muros autocráticos, d Bastilha a Berlim, que hoje podem ser representados pelos altos custos das transações econômicas, as novas barreiras ao progresso, que são mantidas por Estados pesados e gastadores, que querem se perpetuar e as suas castas dirigentes, com todas as perversas exclusões sociais e econômicas que geraram e que mantêm.

Assim, a democracia renovada, que emergiu vitoriosa de três guerras mundiais, não mais poderia ser um mero conceito formal apenas referido à prevalência da vontade da maioria. Historicamente, essa postura havia demonstrado ser perigosa para as conquistas da liberdade, por ser capaz de entronizar os mais ferrenhos radicalismos e despotismos mesmo em sociedades moderadas e cultas.

As duras lições dos conflitos, holocaustos e misérias fizeram prevalecer o conceito substantivo, referido às liberdades fundamentais, que deveriam ser afirmadas mantidas para todos, maioria ou minoria, porque, afinal, a dignidade humana, com seus corolários, que protegem a personalidade, os bens e outros aspectos a ela inerentes, não podem ser objeto de opções de políticas governamentais.

\section{Considerações Econômicas}

Mas não mudaria apenas o cenário político; a Revolução das Comunicações transformaria dramaticamente todo o cenário econômico, causando uma Terceira Revolução Industrial.

Com efeito, a Primeira Revolução Industrial, nos decênios finais do Século XIX, havia assentado o processo de desenvolvimento econômico sobre fatores fixos de produção, tais como os bens imóveis, as máquinas e a mão de-obra local. O papel do Estado correspondi ao modelo liberal clássico, limitando-se a garantir a propriedade e a segurança das transações.

A Segunda Revolução Industrial, no início do Século XX, manteve os fundamentos do desenvolvimento econômico ancorados nos fatores fixos, notadamente baseado em instituições concentradoras de capital e instruico o Estado, em maior ou menor grau, se substituiria aos empreendedores e aos capitalistas privados, aumentando suas receitas tributárías e se assenhoreando dos bens de produção, para dilatar seu poder político, o que inaugurava uma era de capitalismo de Estado.

A Terceira Revolução Industrial, que se iniciou na segunda metade do Século XX fruto da rápida disseminação de altas tecnologias da informação e da produção, deslocou os fundamentos do processo de desenvolvimento para os fatores móveis, como os capitais de investimento institucionalizados, a tecnologia de ponta e a alta qualificação da mão-de-obra, internacionalizados todos, busca de melhores condições de aplicação.

Com isso, o Estado, como agente de produção, ficava alijado da competição diret no setor produtivo, uma vez que os modelos prevalecentes, de Bem Estar Social e Socialistas, já tinham esgotado sua capacidade de retirar já tinham esgotado sua capacidade de retirar
recursos das sociedades que governavam; restava-lhe a alternativa de retirar-se da produção, privatizando ou reprivatizando, e assumir papéis adequados ao novo processo competitivo, atuando como agente regulador e defomento.
Assim, o modelo de Estado Providência, que havia pretendido a tudo prover, acabaria falido, afogado em dívidas, assolado pela inflação, tornando-se incapaz não só de capitanear o desenvolvimento, como até de desempenhar a contento suas tradicionais missões próprias e inalienáveis, de provedor de segurança jurídica, econômica e social.

Um novo modelo surge, em transição, com o abandono do desempenho de atividade econômicas, para as quais a sociedade é comprovadamente melhor do que o Estado, para concentrar-se em regulá-las, no interesse comum, e fomentá-las, ou seja: protegendo e incentivando a concorrência, interna e externamente, dando surgimento a um modelo de Estado Concorrencial.

A globalização rompia o isolamento e a autonomia econômica, que ainda pudessem ser possíveis ao Estado-Nação, deslocando a competição da capacidade bélica para a capacidade de atrair capitais, tecnologias avançadas e cérebros.

Com essa mudança, o Estado, na Terceira Revolução Industrial podia retornar à sua missão própria e insusbtituível de garantir a seguranca da sociedade, o que, no campo econômico, tem um nome: estabilidade.

Antes de levar essas conclusões ao campo financeiro estatal, parece mais apropriado' tecer, agora, algumas consideracões gerais sobre certas relaçõe que se travam entre a democracia e a economia, no contexto das quais se articulam as finanças públicas.

\footnotetext{
${ }^{10}$ A respeito, a conclusão (8.0) do paperreferido, de CATHERINE KUCHTA- HEBLING.
}

"O conceito de Estado Concorrencial está desenvolvido por PHILIP G. CERNY, a partir de seus trabalhos, publicados desde 1991 (The Iimitis of deregulation: transnational interpenetration and policy change, in European Journal of Political Research, 19, p. 173 a 196) até sua maturação em Paradoxes of the Compe State the dynamics of political globalization, in Government and Opposition, 32, 2, p. 251 a 274.

Revista da Faculdade de Direito da UFRGS, v. 21, Março/2002 


\section{A Busca da Estabilidade}

A segurança econômica se assenta em um necessário tripé: a segurança jurídica, que garante a propriedade e os contratos; segurança monetária, que garante a meda, $\mathrm{O}$ crédito e o câmbio,e a segurança fiscal, que garante o equilíbrio das finanças públicas.

Os modelos providencialistas pretéritos, do Estado do Bem-Estar Social e do Estado Socialista, jamais se preocuparam em atender concomitantemente aos três requisitos da segurança econômica. Bastavam-lhes as providências formais da legalidade, do curso forçado da moeda e das finanças públicas orçamentadas.

\subsection{A segurança jurídica}

A busca da segurança jurídica exigia muito mais do que a mera observância da legalidade, entendida em seu sentido formal, pois seria inconcebível que atos de governo, fossem eles normativos ou concretos, não exprimissem a legitimidade das escolhas parlamentares e administrativas, como resultantes da expressão de uma democracia substantiva.

Em outras palavras: só pode existir segurança jurídica quando valores vigentes na sociedade sejam devidamente captados e possam ser implementados na ação do Estado, ou seja, com a evolução do Estado de Direito em Estado Democrático de Direito e a concomitante adoção de princípios jurídicos, que contenham e ponham em evidência uma axiologia moralmente tridimensional: legal, legítima e lícita.

A reunião desses dois qualificativos para distinguir o novo Estado em reconstrução

${ }^{12}$ Para usar a expressão consagrada de PETER HABERLE, v. Verfassung als öffentlicherProzess, Berlim, $2^{\mathrm{a}}$ ed. 1996. ${ }^{13}$ V. art. 18 e $23, \mathrm{G} \mathrm{G}$.

Revista da Faculdade de Direito da UFRGS, v. 21, Março/2002

- democrático e de direito - expunha suficientemente o subjacente conceito constitucional de ordenamento dos valores ${ }^{12}$, tão auspiciosamente inaugurado na Lei Básica de Bonn ${ }^{13}$.

Por outro lado, para a expressão desses valores, sobreveio um intenso repensar dos princípios, de seu conceito, de suas funções e, sobretudo, de sua transcendental importância na estruturação de um Direito visceralmente comprometido com valores substantivos.

Tal mutação, que ocorreria também por volta da segunda metade do Século XX, recuperava para a Ciência Jurídica, um imenso tesouro substantivo, que fora esquecido e quase sepultado pelo positivismo jurídico.

Assim, contribuindo para superar o formalismo positivista, sem que isso significasse abandonar suas conquistas dogmáticas, tão brilhantemente desenvolvidas nos Séculos XIX e XX, e que haviam sido tão importantes para alicerçar a segurança jurídica, os princípios jurídicos, depois de garimpados na doutrina, de onde surgiram, e reconsiderados à luz da epistemologia e da metodologia científica contemporâneas, passaram ao direito posto, na condição de normas jurídicas, com maior amplitude significativa, mas nas mesmas condições formais das normas preceituais.

Essa reentrada dos princípios, a parti de então, passou a demandar um tratamento doutrinário que lhes fosse próprio, e que, pouco a pouco, efetivamente lhes seria dado pelos mais notáveis juristas do século vinte, de modo que, em três decênios, embora um átimo na vida civilizada, logo se comprovaria como a solução adequada para atender os fortes anseios da sociedade pela recuperação dos valores na vida jurídica, ameaçados de se perderem, de tão entulhados pela formidável quantidade de leis produzidas, em multiplicadas fontes legiferantes, paradoxalmente, sepultando o próprio Direito sob montanhas de preceitos jurídicos.

Nada mais enfático, a respeito, que o depoimento de EDUARDO GARCIA DE ENTERRIA, em atualíssima obra, em que aponta a nova dogmática dos princípios como a única técnica que se tornou disponível "para fazer funcionar razoa velm ente o sistema por sobre a maré incessante de inumeráveis preceitos escritos" ${ }^{14}$

Registre-se que, além da pletora legislativa apontada, para o desenvolvimento da nova dogmática dos princípios, concorreram também os seguintes fatos, de não menor importância: a celeridade na mudança dos quadros referenciais (como, por exemplo, na Espanha, que em poucas décadas teve alterado cerca de oitenta por cento do acervo legislativo do País); a ascensão da regulática, trazendo a pluralização e a deslegalização das fontes do Direito; a criação de agrupamentos políticos de Estado em vias de federalização, como a Comunidade Européia, com suas respectivas legislações comunitárias; e, também na mesma linha e não menos importante, o fenômeno em curso da globalização institucional.

É, pois, nesse complexo cenário de nosso tempo que ressurgem os princípios-norma, despontando como o principal instrumento do novo enfoque do Direito, voltado àrecuperação dos valores substantivos da conduta humana,

${ }^{14}$ EDUARDO GARCIA DE ENTERRIA, Justicia y Seguridad Juridica en um Mundo de Leyes Desbocadas, Madri, Civitas, 1999, p. 106

${ }^{15}$ Para uma leitura atualizada a respeito, de HEGE STUCK,Subsumtion und Abwägung. In Archiv für RechtsundSozia/-Phi/osophie, VoI. 84., 1998, ps. 405 e ss.

${ }^{16}$ Como, por exemplo, na obras de HEINRICH HUBMANN (Die Methode der Abwãgung, in Festschrift fä,Ludwig Schnorrvon Carolsfeld zum 70. Geburtstag, Colônia, Berlim, Bonn, Munique, 1973 os. 173 e ss.) e BERNHARD SCHLINK (Abwägung im Veifassungsrecht, Berlim, 1976), esta obra criticada, a propósito, por ROBERT ALEXY, no particular, in Theorie der Grundrechte, Frankfurt a. M., 1996, ps. 141 e 142. em acréscimo aos importantes valores formais, que haviam sido exitosamente implantados pelo positivismo jurídico.

Por outro lado, essa reconsideração dos princípios no Direito importa na conseqüente (ou funcões) que lhes cabe desempenhar na ordem jurídica e, ainda, quando da ocorrência da hipótese de conflitos, a definição, além das técnicas tradicionais de composição interpreceitual, de novas técnicas de composição interprinciolágica, pelo emprego da conciliação ponderada de valore ${ }^{15}$.

Assim é que, sem entrar em maiores detaihes, surgem distinções práticas e que destacam as modalidades de eficácia imediata e mediata dos

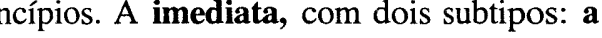
eficácia dirimente e a eficácia impediente, e a mediata, com inúmeros subtipos, como, por exemplo, as eficácias axiológica, nomogenética, otimizadora, sistêmica e integrativa.

Este é, em rápido debuxo, o amplo campo de expansão que o Direito tem à frente, embora deva trilhá-lo com os devidos cuidados para soluções simplistas e radicais, que inevitavelmente surgem como exacerbação de novas idéias, como, por exemplo, as que como já foi sugerido por doutrinadores alemães ${ }^{16}$. preconizam a introdução de métodos 


\subsection{A segurança monetária}

De todos os bens produzidos pela sociedade, a moeda é o mais importante para o sistema econômico: é um bem público, no sentido de pertencer à sociedade e não por se tratar um bem patrimonial do Estado, pois lhe cabe apenas administrála em benefício geral, $e$, por isso, dito sumariamente, o seu valor tanto depende da riqueza gerada pela sociedade quanto da boa gestão monetária.

Mas nem sempre se pensou assim, pois no absolutismo a moeda, que era cunhada pelos reis, a eles pertencia, portando, disso em testemunho, as suas efígies. Mesmo depois das revoluções liberais, notadamente depois da hipertrofia experimentada pelo Estado durante o Século XX, uma persistente deformação estatista sempre se revelou no manejo público totalmente arbitrário da moeda, bastando ao governante invocar nebulosas razões políticas para geri-la em benefício do Estado, quando não de segmentos favorecidos.

Desse vezo resultou o tríplice abuso político das finanças públicas, que caracterizou, afinal, os três inimigos da estabilidade financeira:

O abuso político do orçamento, que é gastar sem receita, criando o deficit público.

O abuso político da moeda, que é emitir sem lastro econômico, gerando a inflação.

O abuso político do crédito, que é contrair dívidas sem recursos assegurados para pagálas, dilatando o endividamento público crítico.

Como a sociedadeé prejudicada, em seu mais delicado patrimônio econômico, que é a saúde da sua moeda, uma vez que essas práticas confiscam-lhe a renda, desestimulam-lhe a poupança e impedem-lhe o desenvolvimento, resultados indesejáveis para qualquer povo, em qualquer época, é indubitável que configuram três insuportáveis agressões ao conceito de democracia substantiva.

Não por outra razão, no Estado Democrático de Direito, patenteou-se necessidade de proteger a higidez econômica dos países, prevenindo a prática de tais abusos, com a instituição da estabilidade econômico financeira, incluindo-a no novo modelo político, como uma categoria de direito subjetivo público difuso do cidadão: em última análise, com o reconhecimento do direito soberano da sociedade de garantir o próprio futuro do País.

\subsection{Segurança fiscal}

O terceiro tripé está nas finanças públicas sadias, pois o Estado gastador e descompensado, no mínimo, intranqüiliza a sociedade e assusta os investidores.

Afastada a acepção antiga e meramente formal de democracia, cumpre estabelecer relação que, hoje, já em sua acepção moderna e material, ela mantém com as finanças públicas, entendida esta expressão, com o amplo sentido de manejo administrativo dos recursos públicos.

E aqui se apresenta outra nefasta confusão semântica, semelhante à apontada para a moeda, entre tantas, aliás, que se puseram a serviço da insegurança e da perpetuação das desigualdades: é que esses chamados recursos públicos, não são assim denominados porque pertençam ao Estado, mas por serem bens do público, ou seja, da própria sociedade, que os gera.

Ora, o proveito público, que vem a ser o resultado esperado da gestão dos recursos entregues ao Estado, se refere primariamente à sociedade, que os produz com sua atividade econômica e a ele os entrega para serem administrados, o que significa, em consequiência, que eles devem ser alocados segundo sua vontade, democraticamente recolhida e legitimamente manifestada, pois é fundamentalmente para atendê-la que essas riquezas, por ela criadas, são arrecadadas.

Pois bem: o instrumento juspolítico necessário para que se proceda a essa alocação democrática de recursos, é o orçamento público, em que são estimadas as receitas a serem arrecadadas, principalmente pela tributação, e fixadas as despesas a serem realizadas em proveito geral. São duas decisões distintas, que devem resultar de ampla e aberta discussão, e jamais serem produtos herméticos, de gabinetes povoados de tecnocratas e de ideólogos de plantão, aplicando fórmulas cerebrinas e empoeiradas.

Em conseqüência, uma vez tomada a decisão democrática conformadorà do orçamento, os administradores passam a responder duplamente à sociedade pela adequada aplicação desses recursos públicos: formalmente, pelo respeito àlegalidade e, materialmente, pelo respeito à legitimidade, das operações orçamentário-financeiras a seu cargo.

Lamentavelmente, na vigência dos modelos predominantes das variedades providencialistas de Estado de Direito, foi tão somente o crivo da legalidade formal aquele que se desenvolveu e apenas através dele se controlou a gestão das finanças públicas. Isso significava que, por muitas décadas, uma vez que o administrador público atuasse de acordo com a lei, ou seja, desde que respeitasse a legalidade, estaria satisfeito o seu dever (formal) de governante.

Como conseqüência, quanto à substância, ou seja, à legitimidadede suas decisões, o administrador público só poderia ser julgado politicamente, pela própria sociedade, quando de novas eleições, até mesmo nos atos de mais aberrante desrespeito do dever material de legitimidade que viesse a perpetrar na administração financeiro-orçamentária. Em todos os casos, reinava a irresponsabilidade substantiva na gestão de dinheiros públicos, e por mais desviada, imprudente e arriscada que fosse, seus atos restavam impunes.

Fácil depreender-se porque, no Brasil, como em tantos outros países do mundo, os políticos ficaram sempre tão marcados na opinião pública pela pecha da irresponsabilidade, e por que se foram acumulando tantas mazelas fiscais, como os déficits públicos, resultantes dos gastos desabridos, além dos recursos disponíveis; a inflação, gerada pela descontrolada emissão de moeda, além dos limites tecnicamente recomendáveis; o endividamento público, acumulado pelo excessivo recurso aos empréstimos, além das possibilidades de solvência regular; os investimentos públicos paralisados, ou por falta de recursos para prossegui-los ou por desinteresse político dos governantes em leválos a cabo; o superfaturamento, como prática desenvolvida para facilitar a prática da corrupção, e a execução de obras inúteis, supérfluas ou indesejadas, mascarando a intenção de prodigalizar favorecimentos inconfessáveis.

Por isso é que a caracterização jurídica de uma responsabilidade fiscal substantiva, que pudesse superar o simples áspecto formal, da mera legalidade, tornou-se um tema juspolítico fundamental dentro da justa ambição, de maior envergadura, da implantação de uma real democracia material, com a esperança e a inspiração alimentadas nas experiências de outros países, que, de algum modo, já logram algum progresso no difícil caminho do aperfeiçoamento da legitimidade. 


\section{O Novo Conceito de \\ Estabilidade e de}

\section{Responsabilidade Fiscais}

Como se expôs, a introdução do conceito renovado de democracia objetiva e substantiva, superando o vigente na paleodemocracia, que era então subjetiva e formal, foi, sem dúvida um notável avanço que se logrou alcançar com a entronização do Estado Democrático de Direito, provocando uma profunda mutação de enfoque político que, rapidamente, se difundiria a partir do Segundo Pós-Guerra.

Esse fenômeno pode ser particularmente identificado no crescente interesse dos países da Europa continental pelas instituições públicas anglo-saxônicas, densamente impregnadas de uma histórica orientação pela democracia substantiva, notadamente no que toca à ação da administração pública, o que ficou nitidamente patenteado no esforço desenvolvido em vários países do Velho Mundo para adaptá-los aos sistemas romanogermânicos neles prevalecentes, o que foi feito, ate mesmo, com algumas aberturas em sua Constituições.

Ainda mais especificamente, tal tendência éfacilmente identificada na intens divulgação e na proliferação que tiveram certos institutos juspolíticos de participação que ganharam presença em toda a Europa, a começar pela Itália, a partir dos últimos anos da década de sessenta, do Século XX.

${ }^{17}$ MIGUel SÁNCHEZ MORÓN, op. cit, in Nota Preliminar, p. 12.

${ }^{18}$ Florença, 1968, Vol. IV, ps. 520 e ss.

${ }^{19}$ Ilprivato e il procedimento amministrativo, Archivo Giuridico, 1970, págs. 25 a 188.

${ }^{20}$ La partecipazione democratica nell'ordinamento regionale, Foro Amministrativo, 1972, VoI. IV, ps. 875 e ss. ${ }^{21}$ La partecipazione amministrativa, Milão, 1973.

${ }_{22}$ Contributo alla definizione del concetto di partecipazione nell'art. 3 della costituzione, Nápoles, 1974.

${ }^{23}$ Riflessione critiche sulle azioni popolari comme struturamento di tutela deglí interessi colletivi, in Rivista Trimestrale di Diritto Pubblico, 1974, número 4, ps. 1395 e ss.

${ }^{24}$ La partecipazione dei privati al procedimento amministrativo nell'esperienza statunidense, in La tutela degli interesse diffusi nel diritto comparato, Milão, 1976.

Revista da Faculdade de Direito da UFRGS, v. 21, Março/2002
Nas finanças públicas, todavia, esse progresso foi mais lento. Somente um século depois de se lograr a primeira abertura democrática no campo do controle fiscal, com a juridicização do orçamento e das contas públicas, ainda sob ocritério de legalidade, se introduziria uma rigorosa disciplina do gasto público sob o critério de legitimidade, para a realização do equilíbrio das contas públicas.

Esse novo passo importava na ampliação da responsabilidade legal, dos governantes e dos administradores públicos, em geral, com a dilatação dos marcos políticos e administrativos que já haviam sido postos pelo Estado de Direito, introduzindo-se parâmetros inovadores, de responsividade legítima, indispensáveis à realização do Estado Democrático.

Por outro lado, indubitavelmente, o que mais acicatou esse surto de desenvolvimento democrático, notadamente em busca do que hoje já se passou a denominar, apropriadamente, de boa administração ${ }^{25}$, foi uma razão um pouco menos nobre, mas que veio a se tornar pandêmica depois da Segunda Guerra Mundial: a insolvência pública.

Essa generalizada insolvência pública, produzida pelos gastos crescentes exigidos para sustentar os- modelos de Estado dominantes, os do Bem Estar e Socialistas, ao mesmo tempo em que progressivamente se reduzia a sua capacidade de captação de recursos, forçava, em muitos casos, a emissão inflacionária, como tentativa de preservar os modelos desgastados e sustentar os regimes políticos existentes.

Mas isso passava a ser uma tarefa cada vez mais difícil, naqueles países, fossem

${ }^{25}$ Expressão utilizada por RAFFAELLE RESTA, em seu livro L'Onere della Buona Amministrazione, publicado em 1940.

${ }^{26}$ Ref. a MANUEL CASTELLS - The Age of Information: Economy, Society and Culture, publicada em português pela Editora Paz e Terra A Era da Informação: Economia Sociedade e Cultura. vencedores ou vencidos, que tanto haviam sangrado e exaurido seus erários com esforços bélicos e com ambiciosos programas assistenciais, prosseguir na crescente arrecadação de tributos: o modelo econômico sgotado haveria de determinar a mudança dos modelos políticos ultrapassados.

Foi, todavia, nas novas democracias emergentes do pós-guerra, exatamente naquelas sociedades que voltavam a recuperar seu espaço político decisório e relutavam a ceder, pela via da tributação pesada, seu espaço econômico decisório privado, que haviam reconquistado com tantos sacrifícios, que o discurso político de cunho conservador, favorável àsustentação das mega-estruturas estatais, se tornou particularmente mais problemático.

Realmente, se, de um lado, no tocante à sociedade, o fato mais importante do período tinha sido a ampliação da consciência cidadã, marcando o início da Era da Informação e, no caso, uma nova concepção de democracia participativa $^{26}$, por outro lado, por parte do Estado, com o progressivo esgotamento dos recursos impositivos disponíveis, não só para financiar suas atividades tradicionais, como para atender às novas demandas dessas sociedades, que despertavam para um novo papel político, alcançava-se o ponto de inelasticidade da carga tributária, entrando-se em um período em que a disseminada insolvência pública seria das mais importantes causas das transformações que se sucederiam.

Essas mudanças marcariam, assim, o fim das variedades hegemônicas, belicistas e providencialistas, do modelo de Estado do Século XX, falidas e esgotadas, sobretudo, pela 
impossibilidade de seguir capitaneando o processo de desenvolvimento.

Mas todos esses aspectos, referentes às mudanças na sociedade no Estado, podem ser mais claramente captados e compreendidos sob a óptica dos princípios, como a seguir se exporá, notadamente quando aplicados ao Direito Financeiro.

\section{Evolução dos Princípios \\ Aplicáveis ao Direito Financeiro Contemporâneo}

Trata-se do desenvolvimento, no contexto de uma robusta renovação dos valores no Direito contemporâneo, de uma principiologia apropriada a esse novo Direito Financeiro, para um Estado Democrático de Direito.

Têm-se, efetivamente, debuxado um quadro fundamental e bem definido, e, até mesmo, no caso brasileiro, elevado ao assent constitucional, em que se distinguem princípios fundamentais, princípios gerais e princípios setoriais.

Com a brevidade própria a um ensaio, apenas se aportará um esboço dessa principiologia básica, para os estritos fins que aqui interessa ao esclarecimento da transição experimentada pelo Direito Financeiro, desde o modelo do Estado de Direito ao do Estado Democrático de Direito, tudo segundo o método e as linhas adotadas para esta exposição.

Segue-se a classificação que se adota na Constituição brasileira de 1988: princípio fundamentais, gerais e setoriais.

\subsection{Princípios fundamentais}

No campo dos princípios fundamentais observa-se uma dupla evolução: do princípio republicano para o princípio democrático e do princípio representativo para oprincípio pa rtici pativo.

6.1.1. Do princípio republicano ao princípio democrático

No Estado de Direito, ganhou destaque o específico conteúdo doprincípio republicano que afirma a coisa pública, como patrimônio comum da sociedade, a ser gerido em benefício de todos.

No Estado Democrático de Direito, em acréscimo, sobressai a importância da decisão pública, o moderno aspecto substantivo do princípio democrático, que afirma o direito de todos e de cada um de compartilhar das deliberações sobre a gestão da coisa pública.

Como se observa, a coisa pública deixa de ser uma longínqua abstração para a sociedade, que, paulatinamente, passa a identificá-la concretamente em relação às suas necessidades, na execução de políticas públicas.

6.1.2. Do princípio representativo ao princípio participativo

No Estado de Direito vige o princípio representativo, que garante a escolha subjetiva, dos dirigentes políticos, pelo sufrágio dos cidadãos.

No Estado Democrático de Direito a ele se soma o princípio participativo, que se volta à escolha objetiva, de como os cidadãos querem ser dirigidos.

Como se exporá adiante, da adoção deste princípio, conjugado com o clássico, da publicidade, deriva o da transparência, que passa a informar todo o setor orçamentáriofinanceiro da Administração Pública.

Está evidente a evolução em curso da democracia, que, sem perder suas bases representativas originais, ganha uma nova e fertilíssima dimensão juspolítica.

\subsection{Princípios gerais}

No campo dos princípios gerais, caracterizam-se três evoluções importantes: a do princípio da legalidade em princípio da legitimidade, a do princípio da eficácia em princípio da eficiência a do princípio da responsabilidade em princípio da responsividade.

6.2.1. Do princípio da legalidade ao princípio da legitimidade

No Estado de Direito entronizou-se o princípio da legalidade, que se expressa na submissão do agir àvontade da lei.

No Estado Democrático de Direito aditase o princípio da legitimidade, que exige, em acréscimo, a submissão do agir à vontade democraticamente captada.

6.2.2. Do princípio da eficácia ao princípio da eficiência

No Estado de Direito importava o princípio da eficácia, vinculando o agi juridicamente correto àprodução de efeitos administrativos.

No Estado Democrático de Direito, além dele, passa a importar também o princípio da eficiência, que vincula o agir juridicamente correto à produção dos melhores efeitos administrativos possíveis, ou seja, à realização da boa administração.
Observe-se, porém, que a eficiência não éapenas mensurável em termos quantitativos, pois o conceito de boa administração está interligado ao da qualidade da prestação devida ao administrado, que é o dono do serviço.

\subsubsection{Do princípio da responsabilidade ao} princípio da responsividade

No Estado de Direito impera o princípio da responsabilidade, que vem a ser, no caso, 0 dever de legalidade, sob o qual, o administrador público responde pela legalidade de seus atos.

No Estado Democrático de Direito se inova o princípio da responsividade, introduzindo um novo dever substantivo, em razão do qual o administrador público também fica obrigado a prestar contas à sociedade pela legitimidade de seus atos.

A responsividade consiste, portanto, na obrigação de o administrador público responder pela violação da legitimidade, ou seja, pela postergação da vontade geral, que foi regularmente expressa, explícita ou implicitamente, na ordem jurídica.

\subsection{Princípios setoriais}

No campo dos princípios setoriais da gestão financeiro-orçamentária, observa-se uma destacada evolução, no que se refere à confecção do orçamento público, que parte do princípio do planejamento para chegar ao princípio do equilíbrio, e, ainda, no que se refere à gestão, a evolução do princípio da moralidade administrativa ao princípio da prudência fiscal, bem como do princípio da publicidade ao princípio da transparência fiscal.

6.3.1. Do princípio do planejamento ao princípio do equilíbrio

No Estado de Direito submeteu-se a atividade financeira pública ao princípio do 
planejamento, o que exigia a previsão de receitas e fixação de despesas de custeio e de capital em orçamento público, como lei formal a ser observada.

No Estado Democrático de Direito vaise além, para submeter-se também a atividade financeira e o planejamento públicos ao princípio do equilíbrio, passando-se a exigir que a execução orçamentária se conduza de forma a equilibrar as despesas não só com a realidade da arrecadação da receita como, ainda, às peculiaridades da realidade sócio-econômica, encontradas em cada unidade financeiramente autônoma.

6.3.2. Do princípio da moralidade administrativa ao princípio da prudência fiscal

NoEstado de Direito iniciou-se um lento, mas irreversível percurso de resgate da licitude, como parâmetro ético para a Administração, hoje presente em vários dispositivos constitucionais brasileiros, entre os quais um genérico ${ }^{27}$, que institui o princípio da moralidade na administração pública, que vem a ser a que se exige do bom administrador, e um específico, que prevê o emprego da ação popular para anular ato lesivo à moralidade administrativa ${ }^{28}$.

No Estado Democrático de Direito vaise mais adiante por esse caminho e se define, ainda com mais vigor, um princípio de prudência fiscal, a ser observado por parte do administrador financeiro, mais apropriado à extrema delicadeza ética, que exige o manejo dos recursos que são compulsoriamente entregues pela sociedade à gestão do Estado, diante dos

riscos que podem sobrevir, mesmo no curso de uma gestão moralmente correta.

Demanda-se, portanto, nesse contexto neodemocrático, que o administrador de recursos públicos aja com especial moderação e extremo cuidado, considerando certos riscos, que até poderiam ser assumidos por gestores privados, mas que não podem ser desprezados quando se trata de gestores da coisa pública, daí o conceito de gestão sem riscos ${ }^{29}$.

\subsubsection{Do princípio da publicidade ao princípio} da transparência fiscal

Finalmente, como último, mas não menos importante princípio setorial no contexto do Estado neodemocrático, ou seja, o que se submete ao conceito de democracia substancial, também o princípio da publicidade especializase e passa por uma evolução para derivar-se em um princípio de transparência fiscal, que não mais se trata de um mero um atendimentoformal, a satisfação de um ritual exigido dos administradores públicos, para se constituir numa obrigação material para que eles patenteiem à sociedade, com plena visibilidade, os seus motivos e os seus objetivos, para que as decisões, que houverem de tomar na gestão fiscal dos recursos públicos, possam ser contrastadas sob o crivo democrático da legitimidade.

O princípio da publicidade, conjugado ao da participação, como acima se mencionou, reproduz amplamente em inúmeros institutos participativos da sociedade na gestão orçamentário-financeira, como as audiências públicas, a disposição de meios eletrônicos de acesso ao público, as consultas públicas, etc. ${ }^{30}$

Art. 37, caput, CF

${ }^{28}$ Art. $5^{\circ}$, LXXIII, CF

${ }^{29}$ Como exemplos, na Lei Complementar $\mathrm{n}^{0} 101$, de 4 de maio de 2000 , os artigos $9^{\circ} ; 21 ; 43, \S 1^{\circ} ; 50$, $\S 3^{\circ}$ e $59, \S 1^{\circ}$

${ }^{30}$ Como exemplos, na Lei Complementar $\mathrm{n}^{0} 101$, de 4 de maio de 2000, os artigos $9^{\circ}$, caput, $9^{\circ}$, $\S 4^{\circ}$; 48, caput 48 , $\S$ único; 49; 51 e $56, \S 3^{\circ}, \mathrm{CF}$.

Revista da Faculdade de Direito da UFRGS, v. 21, Março/2002

\section{Precedentes Institucionais}

São vários os precedentes institucionais dessa transformação, mas que vêm aqui referidos apenas para ilustrá-la e para extremar os dois principais sistemas em que se agrupam as soluções juspolíticas voltadas ao o equilíbrio das contas públicas e ao estabelecimento da responsabilidade fiscal dos seus administradores. ${ }^{31}$

O marco inicial pode ser encontrado no turning point econômico da década de setenta, em que se registrou o abandono do modelo keynesiano de desenvolvimento a cargo do Estado, demarcando o início do processo de revisão do seu papel com relação à moeda e à condução da economia dos países.

Mais concentradamente, no direito positivo, uma providência pioneira específica pode ser identificada na instituição do chamado controle guilhotina do direito norte-americano, na qual já se vai encontrar uma aplicação do princípio do equilíbrio orçamentário, que, de acordo com essa legislação, deve ser obtido por meio de cortes orçamentários a serem aplicados pelo Congresso sobre os gastos excessivos da Administração, tudo no cumprimento de uma política de metas de austeridade fiscal por ele definida.

Esse resultado se garante com o conceito corolário da accountability, entendido como um tipo especial de responsabilidade, que passava a ser exigida dos administradores, inaugurando um modelo parlamentar de controle do equilíbrio das contas públicas. ${ }^{32}$
Sobrevieram outras experiências, como a francesa, a alemã e a argentina, que se inclinaram pela realização do controle de gastos pela própria Administração; neste caso, obedecendo a parâmetros rígidos, que devem ser, para esse efeito, previamente legislados, culminando os exemplos desse sistema de controle, com o mais recente, adotado na Nova Zelândia ${ }^{33}$, instituidor da chamada administração sem riscos fiscais, partícularmente importante para o Brasil por ter servido de modelo ao Projeto de Lei Complementar 18/99, que, posteriormente, com os aperfeiçoamentos introduzidos pelo Deputado Pedro Novaes, viria a se transformar na Lei Complementar $\mathrm{n}^{0} 101$, de 4 de maio de 2000 .

Para encerrar esta breve resenha, vale lembrar ainda, por seu conteúdo preceptivo, a receita de boas práticas de transparência fiscal, um documento do FMI, divulgado em 1998, no qual técnicos do Fundo Monetário Internacional apresentam uma orientação sobre o assunto e sobre os princípios afins da transparênciae da prudência na gestão fiscal. ${ }^{34}$

\section{A Institucionalização do Equilíbrio e da Responsa- bilidade Fiscais no Brasil}

Chega-se, então, ao Brasil, com a indagação: o que foi feito e o ainda que resta fazer para que realmente se tenha institucionalizado, a contento, o equilíbrio e a responsabilidade fiscal no País?

${ }^{31}$ A respeito, recomenda-se, como muito proveitosa leitura, de RICARDO LOBO TORRES, o item 2. Gestão Orçamentária Responsável, do Cap. IV. Do Volume V, do Tratado de Direito Constitucional, Financeiro e Tributário, Rio de Janeiro, Editora Renovar, $2^{a}$ edição, 2000, do qual se retirou a demarcação feita entre os dois sistemas de controle da estabilidade financeira: o Parlamentar, norte-americano, e o Executivo, neozelandês (p. 325). ${ }^{32}$ As leis básicas desse sistema norte-americano estão no Gram-Rudman-Holings Act, de 1985, ou Balanced Budget and Deficit Reduction Act, no Omnibus Balance Recondiation Act e no Budget Enforcement Act, ambos de 1990. ${ }_{33}$ Trata-se do Fiscal ResponsabilityAct, de 1994.

${ }^{34}$ Código de Buenas Prácticas de Transparência Fiscal, adotado pelo Comitê Provisório, em abril de 1998. 
Ora, como é ressabido, os aspectos dominantes nas finanças públicas brasileira foram sempre e secularmente fincados em nossa cultura, o patrimonialismoe o personalismo, a que se acrescentou mais tardiamente a democracia formal, produzindo esse amálgama em suas formas mais radicais, o fenômeno que caracteriza entre nós o velho caciquismo político.

As conseqüências dessas heranças, até hoje de todo inafastadas, têm sido a crônic imprevisão, a improvisação administrativa, $o$ apelo à demagogia fácil, a multiplicação de obras inconclusas, o acúmulo de déficit públicos, e, até bem recentemente, os males da inflação e do endividamento crescente. Tudo, em suma, compondo o quadro do desequilíbrio das contas públicas e da irresponsabilidade fiscal, a ser revertido.

O primeiro marco de racionalização dos gastos públicos no Brasil data da Constituição Imperial, de 1824 , com a instituição do orçamento, que foi agasalhada nas Cartas republicanas e até ampliada substancialmente na Constituição autocrática de 1937. Mas não se pode dizer que sua trajetória tenha tido sucesso, pois as antigas leis de meios continham sempre os mesmos defeitos, que se combinavam de vários modos: a politização excessiva, a hegemonia do Poder Executivo, as caudas orçamentárias indevidas e irreversivelmente, a descontinuidade das políticas públicas e as portas abertas para os gastos desabridos. Em suma, o orçamento servia muito mais aos políticos que à sociedade.

Assim é que o primeiro grande marco de efetiva racionalização só chegou com a promulgação do Código de Contabilidade
Pública da União, que continha, à época, ate mesmo, uma previsão de crime de responsabilidade fiscal.

Um longo aprendizado, demasiado longo, encontrou, enfim, um grande momento, com a Lei $\mathrm{n}^{0} 4.320$, de 1964 , que introduziu normas gerais para o direito financeiro, instituiu o orçamento-programa e nos legou, praticamente, o modelo norte-americano, baseado nos conceitos de planejamento de Estado, de continuidade da inversão de capital, e da obrigatoriedade da realização do empenho para proceder às despesas.

E este ciclo arrastado e preguiçoso que Complementar $\mathrm{n}^{0} 101$, de 4 de maio de 2000 , que introduziu, também sob inspiração remota de aperfeiçoamentos norteamericanos, o princípio setorial do equilíbrio das contas públicas e os conceitos da responsabilidade e da responsividade fiscais.

A inspiração próxima, da lei fiscal da . Nova Zelândia, de 1994, por suas características políticas, deslocando o controle do Congresso para o Executivo, embora isso possa ser irrelevante em países parlamentarístas, reforça este Poder, dando-lhe uma função relevante e de apreciável preeminência no processo orçamentário-financeiro das unidades da Federação ${ }^{35}$.

Essa origem próxima, a que se acrescem alguns defeitos de elaboração legislativa, são problemas sucintamente relacionados nas conclusões que se seguem, em que se procura ponderá-los, com neutralidade, em face das soluções vantajosas que aporta ao Direito Financeiro nacional. se completa, trinta e seis anos depois, com a Lei

${ }^{35}$ Exemplo eloquiente da preeminência a que se alude está clarissimamente posta no art. 90, § 3, da Lei Complementar $\mathrm{n}^{0} 101 / 2000$, ao "autorizar" o Poder Executivo a "limitar os valores financeiros segundo os critérios estabelecidos pela lei de diretrizes orçamentárias", o que nada mais é que um mandato legislativo para intervir corretivamente sobre os demais Poderes.

Revista da Faculdade de Direito da UFRGS, v. 21, Março/2002

\section{Conclusões}

Infelizmente, embora politicamente avançada, historicamente oportuna, tecnicamente necessária e, indubitavelmente, útil à economia e ao desenvolvimento do País, a nova Lei apresenta problemas que ameaçam comprometer não apenas sua implantação, como, o que poderia ser ainda pior, os próprios conceitos modernizadores da democraci substantiva brasileira que procura introduzir.

Possivelmente, a esta altura, até os leigos, pela simples leitura dos jornais, já se têm dado conta de alguns dos inúmeros percalços que são devidos aos inúmeros defeitos da nova legislação.

Com efeito, em que pese todo seu inegável mérito: ela é prolixa, excessivamente tecnocrática em seu conteúdo, demasiadamente remissiva em sua redação, apresenta dificuldades, tanto para sua compreensão como para sua implementação, além de outros problemas que decorrem de uma forçada simetria federativa e, de outros, passageiros, que são causados pela escassez de regras transitárias.

Com efeito, trata-se de diploma muito prolixo, desenvolvendo-se em longos 75 artigos, enquanto, por exemplo, a Lei Argentina, em contraste, não passa de 8 artigos. Já se vem tornando comum, no País, os textos legislativos longos, detalhistas e tantas vezes casuísticos, como se houvesse desconfiança quanto ao trabalho dos intérpretes; uma postura inaceitável, que degrada e que suscita mais problemas do que os resolve, em razão da intrínsica conflítualidade que lhes é inevitável e diretamente proporcional à enxúndia.

Peca, outrossim, por ser excessivamente tecnocrática, denotando claramente a retração da devida assistência jurídica em sua redação. A este respeito, o Professor RICARDO LOBO TORRES tem observado, em suas excelentes conferências e intervenções, em painéis que vem apresentando sobre esta Lei, que a primeira versão apresentada não passava de uma tradução grosseira, pejada de horríveis anglicismos e de erros de português, da referida Lei Fiscal da Nova Zelândia, de 1994, que lhe servira de modelo.

Descuido de origem semelhante levou a que ainda, a Lei Complementar um diploma se tornasse, excessivamente remissivo, o que causa imensa dificuldade para o entendimento claro de seu conteúdo e para sua implementação, o que vem ocorrendo praticamente em todos os Estados e Municípios, e que, por óbvio, mais se agrava nas unidades menores.

$E$ às vacilações na compreensão e na implementação dessa Lei Complementar, somase também o defeito recorrente de não se levar em conta a real assimetria federativa do País, tratando-se com os mesmos métodos e instrumentos as finanças e a contabilidade públicas da União, dos Estados e Municípios, independentemente de suas limitações e idiossi ncrasias.

Finalmente, para encerrar a relação, a Lei apresenta problemas de inconstitucionalidade, que, não obstante, poderão ser até superados, por via de interpretações segundo a Constituição, como recentemente o foi, na apreciação, pelo Supremo Tribunal Federal, a fixação de limites internos para o dispêndio dos Poderes dos Estados e dos Municípios è de seus órgãos financeiramente autônomos.

Todavia, durante este processo de exame de constitucionalidade, que poderá demorar-se, vai se também prolongando um nefasto e desastrado clima de dúvidas e de desestímulo.

Por outro lado, seria imperdoável que esta geração perdesse a oportunidade histórica de colher as vantagens da racionalização $e$ democratização financeira e se quedasse numa postura crítica negadora ou acomodada. 
É preciso, pois, desenvolver um grande esforço nacional para ampliar a consciência da necessidade de cultivar os valores introduzidos com a Lei Complementar ${ }^{0} 101$, de 4 de maio de 2000, e de aperfeiçoá-la em sua execução, no que possível, o que comporta várias linhas de ação, tais como:

a - questionar no Judiciário os temas que sejam mais constitucionalmente delicados, visando a obter liminares tranqüilizadoras, num ou noutro sentido, pacificando a aplicação da nova legislação em seus pontos mais polêmicos;

b-pressionar-se o Poder Público para a eventual reabertura de processo legislativo específico sobre os temas em que se revele maior necessidade de correções e de aperfeiçoamentos, o que poderia e deveria então, ser realizado com a maior participação possível da classe jurídica, da qual, lamentavelmente, ela careceu na sua origem, e

c-estimular-se a promoção de debates e de reuniões de estudo, visando ao desenvolvimento de uma metodologia de aplicação simples e clara.

Sem dúvida, em qualquer das linhas de ação, vale em sua plenitude o esforço que puder ser feito, porque, inegavelmente, a prática salutar do equilíbrio fiscal e a mudança da mentalidade cívica, que advirá como resultado, consolidarão, simultaneamente, a economia e a democracia no País.

\section{Arbitragem e contrato administrativo}

\author{
Dr. Eros Roberto Grau
}

Professor Titular da Faculdade de Direito da USP Professor Visitante da Faculdade de Direito da Universidade de Montpellier I (Franca) [1995-1998]

O debate a respeito da juridicidade da solução, mediante arbitragem, de conflitos entre as partes nos contratos administrativos segue inúmeras vezes por vias inadequadas. Os argumentos em favor e contra a adoção do instituto da arbitragem nesses contratos não atingem, em regra, o núcleo da questão.

O seu deslinde reclama o exame de três pontos, o primeiro deles extremamente singelo.

\section{Jurisdição e Arbitragem}

O primeiro aspecto a considerar está em que a arbitragem não encerra jurisdição ${ }^{1}$.

Ao contrário, a arbitragem previne a jurisdição. Sua origem é contratual ${ }^{2,3}$

Desfaça-se de pronto, pois, a confusão freqüentemente estabelecida entre uma e outra.

Entre outros, PIERO CALAMANDREI, Instituciones de Derecho Procesal Civil, trad. Sentis Melendo, Buenos Aires, El Foro, 1.996, vol. II, p. 279; SALVATORE SATTA, Manual de Derecho Procesal Civil, trad. Sentis Melendo, Buenos Aires, EJEA, 1.972, vol. II, p. 289 e J.J. CALMON DE PASSOS, Da Jurisdição, Salvador, Progresso, 1.957, p. 46

Nesse sentido, o magistério de CALMON DE PASSOS (Da Jurisdição, Salvador, Progresso, 1.957, pág. 46): "De tudo se conclui, na verdade, que os árbitros não têm jurisdição. E porque não a têm é que os autores, diante da perplexidade, procuram fugir com afirmativas de nenhum conteúdo, quais as de jurisdição extraordinária, ou menos plena, ou quase ordinária. Não têm jurisdição, disse-o Manoel Gonçalves da Silva, com propriedade que Pontes de Miranda ressalta elogiosamente, porque apenas conhecem jurisdicionalmente das causas que thes são submetidas - 'neque jurisdictione habent, sed tantum cognitionei'. Jurisdição é conhecimento (ratio), julgamento (judicium) e execução (imperium) do julgado. Ausente qualquer desses elementos não há jurisdição', $\mathrm{O}$ laudo arbitral, ensina Redenti, em si e por si, não pode ser tido como sentença, porque os árbitros não são investidos de uma função pública e muito menos de um poder soberano, donde o seu pronunciamento, em si e por si, não ser munido de nenhuma autoridade ou eficácia própria, originária.

3 Há quem pretenda que a arbitragem tenha cunho jurisdicional, como NELSON NERY JR., Princípios do Processo Civil na Constituição Federal, $3^{\mathrm{a}}$ ed., São Paulo, Saraiva, 1.996, p. 75. O argumento de que lança mão esse autor não impressiona, contudo. $O$ fato de o laudo arbitral constituir título executivo e transitar em julgado é absolutamente irrelevante. A transação celebrada para prevenir um litígio também faz coisa julgada entre as partes (art. 1.030 do CCB) e é título executivo. Mas ninguém irá tão longe, a ponto de atribuir caráter jurisdicional a esse negócio jurídico.

Revista da Faculdade de Direito da UFRGS, v. 21, Março/2002 